\title{
The Effects of Thyroidectomy on the Wheel Running Activity of Female Rats'
}

\author{
JEFFREY J. STERN \\ University of Michigan, Dearborn, Michigan 48128, U.S.A.
}

(Received 2 June 1970)

\begin{abstract}
SteRn, J. J. The effects of thyroidectomy on the wheel running activity of female rats. PHYsiol. Behav. 5(11) 1277-1279, 1970. - The wheel running activity of female rats was observed prior to and following thyroidectomy. Thyroidectomy significantly reduced overall activity and increased the interval between activity peaks; thyroid feeding corrected these effects. Thyroid feeding did not correct the effects in ovariectomized rats. The continued administration of estradiol benzoate and progesterone increased activity in ovariectomized-thyroidectomized rats. The results suggest that the activity reduction consequent to thyroidectomy is not a direct result of thyroid removal but an indirect result mediated by altered ovarian functioning.
\end{abstract}

Thyroidectony Wheel running activity Activity Ovariectomy Sex hormones

THE THYROID gland influences the wheel running activity of female rats. Total thyroidectomy reduces the activity of the female, abolishes its cycles, and the administration of thyroid extract corrects these effects [6]. Thriouracil, a thyroid inhibiting drug, abolishes the females' cycles and reduces wheel running activity [5].

Removal of the thyroid affects the functioning of the ovary. Following thyroidectomy the appearance of vaginal cornification is irregular and the intervals between estrus are lengthened [5]. Since the ovary is known to influence activity [8], the possibility exists that the activity changes consequent to thyroidectomy are not a direct result of thyroid removal but an indirect result mediated by altered ovarian functioning. The present study tested this possibility by examining the effects of thyroid feeding and subsequent ovarian hormone administration on the wheel running activity of thyroidectomized and ovariectomized rats.

\section{METHOD}

The animals were 12 virgin female albino rats. At the start of the experiment the females ranged in age from 90 to 117 days and weighed $197-227 \mathrm{~g}$. Rat chow and water were constantly available. The laboratory had a thermostat which maintained the temperature at approximately $74^{\circ} \mathrm{F}$. The rats were on a reversed $12 \mathrm{hr}$ on-12 hr off light cycle with lights off at $10 \mathrm{a} . \mathrm{m}$.

The females were initially given an adjustment period of 10-14 days in the activity cages. Following this and continuing throughout the experiment, revolutions per day (RPD) were recorded daily at approximately $9: 30$ p.m. On the 29 th recorded day (Table 1) 9 females were thyroidectomized while 3 were sham operated. These operations and those to follow were conducted under Nembutal anesthesia. Three weeks after the thyroidectomies (Day 50) the females in Groups 1, 3 and 4 had thyroid extract added to their diet. The thyroid extract and rat chow were powdered in a mortar; $30 \mathrm{~g}$ of extract to $1000 \mathrm{~g}$ rat chow. From Day 30 until Day 70 vaginal smears were taken each night at approximately 9:00 p.m. The females in Group 2 had smears taken until Day 50 at which time they were eliminated from the study. On Day 70, six females (Groups 1 and 4) were ovariectomized while three (Group 3) were sham ovariectomized. Thyroid feeding was discontinued on Day 90 . On the morning of Day 102 the females were placed on the hormone regime shown in Table 2. The dosages of estradiol benzoate and progesterone administered were based on preliminary work which indicated that these were the minimal amounts to reliably induce sexual receptivity in $200 \mathrm{~g}$ ovariectomized females. The administration schedule was an attempt to maintain small and constant titers of hormone [9].

\section{RESULTS}

Thyroidectomy produced two changes in wheel running activity. The first was a reduction in total activity. A comparison of RPD for the three weeks prior to the thyroidectomy with RPD for the three weeks following surgery reveals a significant decrease in activity for 8 of the 9 thyroidectomized animals ( $t$ tests). These differences were found even if the pre- and post-operative activity peaks were eliminated from the data analysis. A comparable decrease in activity was not found in the sham thyroidectomized group (Fig. 2).

The second postoperative change was an increase in the interval between activity peaks. Following thyroidectomy the females in Groups 1, 3 and 4 had activity peaks separated

'This research was funded by a University of Michigan Horace H. Rackham School of Graduate Studies grant. The hormones were generously supplied by the Schering Corp., Bloomfield, N.J. 
TABLE 1

DESIGN OF THE EXPERIMENT

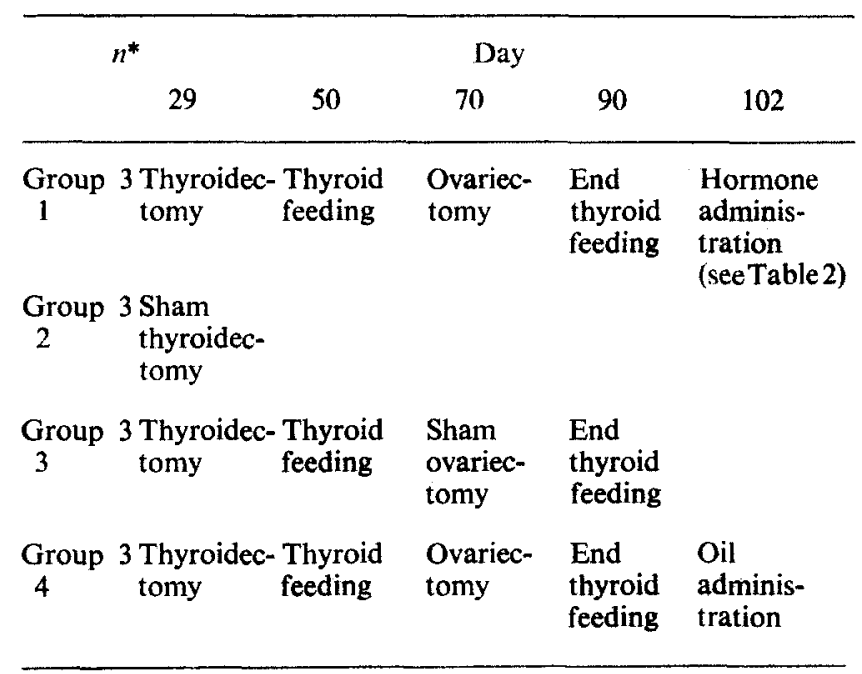

* Since the completion of this study the basic findings have been extended to an additional 4 animals.

TABLE 2

Schedule of Hormone Administration*

\begin{tabular}{lll}
\hline & $\begin{array}{c}1 \mu \mathrm{g} \text { Estradiol } \\
\text { Benzoate }\end{array}$ & $0.4 \mathrm{mg}$ Progesterone \\
\hline Days & 102,103 & 104 \\
Days & $105,106,107$ & 108 \\
Days & $109,110,111$ & 112 \\
Days & $113,114,115$ & 116 \\
Days & $117,118,119$ & 120 \\
Days & $121,122,123$ & 124 \\
\hline
\end{tabular}

*All injections given subcutaneously at 10.00 a.m.

by $5-14$ days $(M=7.8)$ in contrast to the $2-5$ day $(M=4.3)$ intervals which characterized the females prior to surgery. The sham thyroidectomized females continued to show 4-5 day peaks postoperatively. The females in Groups 1, 3 and 4 had 24 peaks from the day of thyroidectomy until the commencement of thyroid feeding. Twenty of these peaks occurred during vaginal cornification while four occurred during a stage characterized by nucleated epithelial cells and leucocytes. Three of these diestrus smears were taken from the sameanimal.

The vaginal smears taken from the thyroidectomized females for days 30-50 reveal certain irregularities. The estrous cycles were longer than normal and agreed with the animal's activity cycles e.g. the longer the period between activity peaks the longer the period between the presence of cornified cells. During the no peak periods the smears were characterized by epithelial cells and leucocytes while during the activity peaks the smears were characterized by cornified cells. In 3/20 cases the cornified cell stage was present for 2 successive days while in one instance it appeared for 3 successive days.
In each of these cases, however, the activity peak occurred only on the first day of cornification. The smears taken from the sham thyroidectomized females were not atypical.

Thyroid feeding corrected the effects of thyroid removal. Seven of the 9 females in Groups 1,3 and 4 showed a significant increase in activity during the initial 20 days of thyroid feeding while 1 (S9, Group 3) showed a significant decrease. This last female was the same animal that failed to show a post thyroidectomy activity decrease. An autopsy performed on $\mathbf{S 9}$ at the termination of the experiment revealed large amounts of thyroid like tissue still present. In addition to increasing overall activity, thyroid feeding returned the females to their 4-5 day activity cycles (Figs. 1, 3 and 4). Finally, the vaginal smears taken from day 50 to day 70 showed cornification every 4-5 days.

Ovariectomy reduced overall RPD and abolished activity cycles in all females (Figs. 1 and 4). Sham ovariectomy did not produce these effects (Fig. 3).

With the initiation of hormone treatment there was an increase in overall activity (Fig. 1). Oil administration did not produce these effects (Fig. 4). The activity peaks which appeared during this period for $\mathbf{S 2}$ corresponded with progesterone administration (Table 1, Fig. 1). The peaks of the remaining animals in Group 1 were not as closely correlated with progesterone treatment. These animals exhibited 9 activity peaks during the period of hormone administration. Of these 9 , only 4 corresponded with progesterone administration.

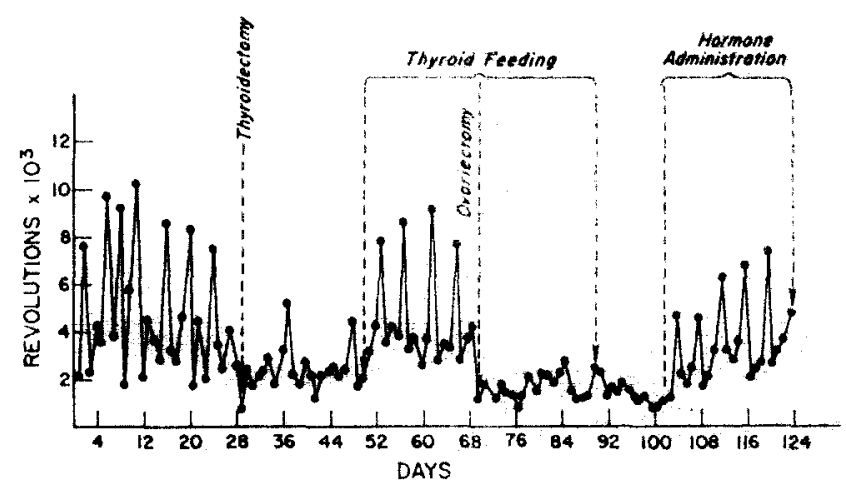

FIG. 1. Revolutions per day for S2 (Group 1).

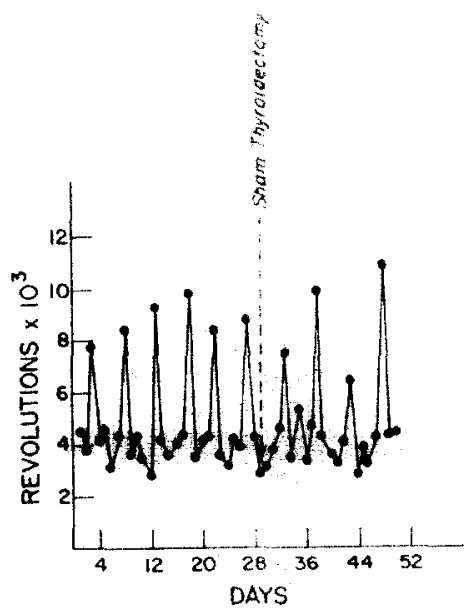

FIG. 2. Revolutions per day for S5 (Group 2). 


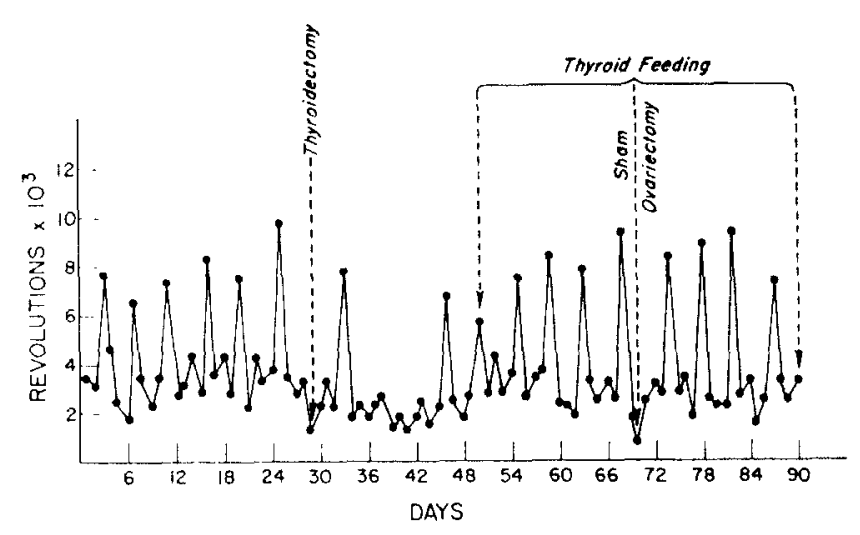

FIG. 3. Revolutions per day for S7 (Group 3).

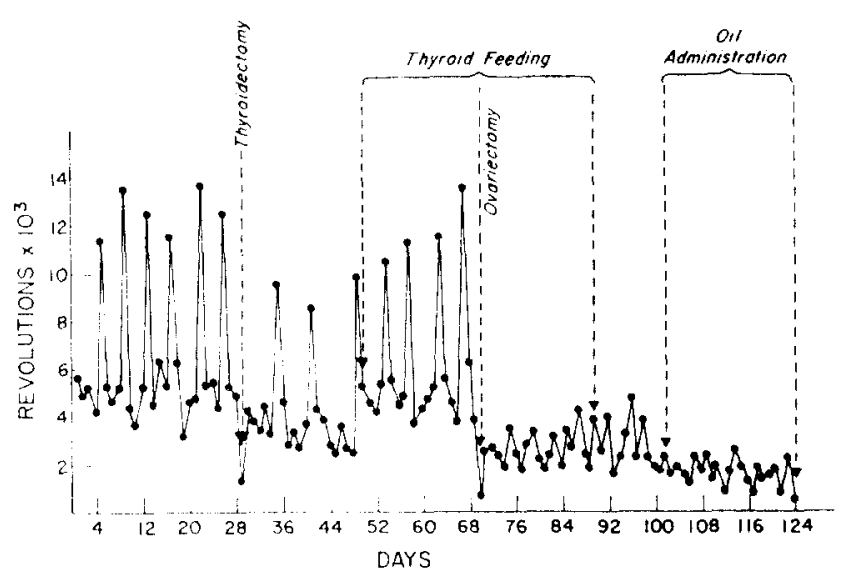

FIG. 4. Revolutions per day for S11 (Group 4).

\section{DISCUSSION}

The present findings agree with those of Richter [6] and Mann [5]. Thyroid removal reduces overall activity and increases the interval between activity peaks. Thyroidectomy disrupts ovarian functioning as judged by vaginal smears.
The appearance of activity peaks following thyroidectomy continues to correspond with vaginal cornification ([5], p. 96). Finally, thyroid feeding corrects the effects of thyroid removal.

Richter states ". . . the reduction of activity after thyroidectomy is due to a lack of thyroid secretion...." p. 79. However, two lines of evidence from the present study suggests that the major decrease in activity following thyroidectomy is due to a lack of ovarian secretions. (1) Thyroid extract will not maintain activity levels in thyroidectomized-ovariectomized females. (2) Ovarian hormones will re-establish activity levels in thyroidectomized-ovariectomized females.

It is well established that ovariectomy reduces base line activity $[8,9]$. The present report differs from previous ones, however, in that it controls for possible post ovariectomy thyroid changes. This was controlled by ovariectomizing females that were already thyroidectomized and that were being fed sufficient thyroid extract to otherwise maintain activity levels.

The finding that estradiol benzoate followed by progesterone increases activity contrasts with a finding of Young and Fish [9]. They report that neither estradiol benzoate nor estradiol benzoate followed by progesterone is effective in restoring running activity in ovariectomized females. Certain procedural differences e.g. dosage of estradiol benzoate, timing of injections, however, make a direct comparison difficult.

The present data demonstrate that the activity changes following thyroidectomy are not a direct result of thyroid removal but an indirect result mediated by altered ovarian functioning. Thyroid removal may affect the ovary directly e.g. low thyroxine hinders ovarian steriod production. Alternatively, thyroid removal may affect the ovary indirectly via the pituitary: In addition to increased TSH secretion [4], thyroidectomy may lead to an increase in gonadotrophin secretion. This altered gonadotrophin output results in ovarian dysfunction which in turn produces the observed reduction in activity. Support for the overlapping secretion of gonadotrophins and TSH is provided by studies which report correlated outputs of the hormones. There is an increase in TSH output associated with the ovulatory discharge of lutinizing hormone [2]. Juvenile hypothyroidism in girls is often associated with precocious puberty [7]. Thyroid therapy returns the girls to a prepubescent state. Castrated animals are reported to secrete large amounts of TSH [1]. Finally, animals developing tumors in response to hypothyroidism exhibit marked ovarian stimulation [3].

\section{REFERENCES}

1. Aron, M. and J. Benoit. Influence de la castration sur le taux d'hormone préhypophysaire excito-sécrétrice de la thyroid présent dans dans le milieu intérieur, chez le cobaye. C. r. Soc. Biol. 107: 784-786, 1931.

2. Brown-Grant, K. The relationship between ovulation and the changes in thyroid gland activity that occur during the oestrous cycle in rats, mice and hamsters. J. Physiol. 184: 402-417, 1966.

3. Furth, J. and K. H. Clifton. Experimental pituitary tumours. In: Ciba Foundation Colloquia on Endocrinology, Vol. 12, Hormone Production in Endocrine Tumors, edited by G. F. W. Wolstenholme and M. O'Connor. Boston: Little Brown, 1958, pp. 3-16.

4. Gorbman, A. and H. A. Bern. A Textbook of Comparative Endocrinology. New York: John Wiley, 1962.
5. Mann, C. W. The effect of thiouracil upon the heart rate, estrous cycle, and spontaneous activity of the white rat. $J$. Physiol. 20: 91-100, 1945.

6. Richter, C. P. The role played by the thyroid gland in the production of gross body activity. Endocrinology 17: 73-87, 1933.

7. Van Wyk, J. J. and M. M. Grumbach. Syndrome of precocious menstruation and galactorrhea in juvenile hypothyroidism: an example of hormonal overlap in pituitary feedback. J. Pediat. 57: $417-435,1960$.

8. Wang, G. H. The relation between "spontaneous" activity and oestrous cycle in the white rat. Comp. Psychol. Monogr. 2: 1-27, 1923.

9. Young, W. C. and W. R. Fish. The ovarian hormones and spontaneous running activity in the female rat. Endocrinology 36: $181-189,1945$. 